\title{
PENGARUH KEPEMIMPINAN ETIS(ETHICAL LEADERSHIP),BUDAYA ORGANISASI, DAN PENGHARGAAN(REWARDS) TERHADAP KETERIKATAN KERJA(WORK ENGAGEMENT) ACCOUNT REPRESENTATIVE (AR) PADA KPP PRATAMA DI LINGKUNGAN KANWIL DJP ' $X$ '
}

\author{
Rimon Domiyandra, Hariv Amali Rivai \\ (Program Studi MM FE Universitas Andalas) \\ domiyandra@gmail.com
}

\begin{abstract}
Employee engagement has become an important issue in human resource management because employee engagement is a key driver in realizing organizational goals. Engaged workers can provide sustainable differentiation for the organization and become a significant competitive advantage.

This study aims to examine the influence of ethical leadership, organizational culture, and rewardsto work engagement. The object of this research is the Account Representative (AR) at the tax officeson ' $\mathrm{X}$ ' Regional Tax Offices which amounted to 165 people.

This research is a type of quantitative research that is descriptive. From the nature of the problem this research is correlational research. Data processing is done using the SPSS version 16 application.

The results showed that ethical leadership, organizational culture, and appreciation had a significant and positive influence on work engagement.

From the results of this study it is suggested that organizations give serious attention to efforts to realize the character of ethical storage in their managers, build and implement organizational culture, and develop various forms of appreciation for employee performance, both financial and non-financial awards in order to improve work engagement of employees.
\end{abstract}

Keywords: ethical leadership, organizational culture, rewards, work engagement

\begin{abstract}
ABSTRAK
Keterikatan kerja pegawai telah menjadi isu penting dalam pengelolaan sumber daya manusiakarena keterikatan pegawai merupakan pendorong kunci dalam mewujudkan tujuan organisasi. Tenaga kerja yang engage mampu memberikan diferensiasi berkelanjutan bagi organisasi dan menjadi keunggulan kompetitif yang signifikan.

Penelitian ini bertujuan untuk menguji pengaruh kepemimpinan etis, budaya organisasi, dan penghargaan terhadap keterikatan kerja. Objek penelitian ini adalah Account Representative (AR) yang ada pada Kantor Pelayanan Pajak Pratama di lingkungan Kantor Wilayah DJP ' $\mathrm{X}$ ' yang berjumlah 165 orang.

Penelitian ini merupakan jenis penelitian kuantitatif yang bersifat deskriptif. Berdasarkan sifat permasalahannya penelitian ini merupakan penelitian korelasional. Pengolahan data dilakukan menggunakan aplikasi SPSS versi 16.

Hasil penelitian menunjukkan bahwa kepemimpinan etis, budaya organisasi, dan penghargaan memiliki pengaruh yang signifikan dan positif terhadap keterikatan kerja.

Dari hasil penelitian ini disarankan supaya organisasi memberikan perhatian yang sungguh-sungguh terhadap upaya merealisasikan karakter kepemimpan etis di dalam diri para manajernya, membangun dan mengimplementasikan budaya organisasi, serta mengembangkan berbagai bentuk penghargaan terhadap kinerja pegawai, baik penghargaan bersifat finansial maupun non finansial dalam rangka meningkatkan keterikatan kerja pegawainya.
\end{abstract}

Kata kunci : kepemimpinan etis, budaya organisasi, penghargaan, keterikatan kerja 
Jurnal STIE SEMARANG VOL 11 No 1 Edisi Februari 2019 (ISSN: 2085-5656, e-ISSN :2232-7826)

\section{PENDAHULUAN}

Keterikatan kerja (work engagement) pegawai telah menjadi isu penting dalam pengelolaan sumber daya manusia untuk mewujudkan tujuan organisasi. Menurut Lockwood (2007) engagement pegawai merupakan pendorong kunci menuju keberhasilan organisasi. Tingkat engagement yang tinggi dapat meningkatkan kinerja organisasi.

Engagement didefinisikan sebagai pemikiran positif terhadap pekerjaan yang ditandai dengan semangat, dedikasi, dan keterikatan yang mendalam dengan pekerjaan (Schaufeli, Salanova, dan Bakker, 2002). Seorang pegawai yang engage adalah pegawai melakukan pekerjaannya dengan antusias, penuh semangat, berdedikasi tinggi, hingga larut dalam pekerjaan bahkan sampai tidak memperhatikan waktu.

Pegawai yang tidak engage cenderung akan memiliki perilaku-perilaku negatif seperti tidak bekerja dengan efektif dan efisien, tidak menunjukan komitmen penuh dalam pekerjaannya, tidak memiliki inisiatif untuk melakukan perubahan dalam organisasi, serta selalu merasa khawatir ketika dilakukan evaluasi terhadap dirinya (White, 2006).Sikap dan perilaku demikian akan menyia-yiakan banyak sumber daya organisasi dan akan menjadi penghambat organisasi dalam menjalankan strategi mencapai tujuannya.

Engagement pegawai dipengaruhi oleh banyak faktor, di antaranya budaya tempat kerja, gaya komunikasi dan pengelolaan perusahaan terhadap kepercayaan dan penghormatan, kepemimpinan, dan reputasi perusahaan (Lockwood, 2007), bentuk penghargaan yang dijalankan organisasi (Hanim, Zulhafiza, dan Zulfadhli, 2016). Menurut Benazir (2015) engagementpegawai sangat dipengaruhi oleh kepemimpinan, budaya tempat kerja, reputasi perusahaan, dan praktek penghargaan.

Direktorat Jenderal Pajak (DJP) pernah melakukan survei tentang engagementpara pegawainya, yaitu pada tahun 2010 dan 2013. Employees Engagement Survey (EES) Direktorat Jenderal Pajak tahun 2010 yang diikuti oleh 14.545 orang pegawai atau $44 \%$ dari total pegawai menunjukkan hasil bahwaterdapat76\% pegawai yang engage, $19 \%$ pegawai passively engaged, dan 5\% pegawai actively disengaged. EES DJP tahun 2013 yang diikuti oleh 11.920 orang pegawai atau $39 \%$ dari total pegawai menunjukkan hasil bahwa terdapat $35 \%$ pegawai engage, $26 \%$ pegawai disengaged, dan sebesar $38 \%$ pegawai unsatisfied. Data di atas menunjukkan engagement pegawai di lingkungan DJP relatif tinggi karenaState of the Global Workplace Report(2013) melaporkan bahwa pegawai yang engage di seluruh dunia hanya sekitar $13 \%$ dari jumlah total pegawai. Laporan tersebut bahkan menyatakan bahwa di Indonesia hanya $8 \%$ pegawai yang tergolong engaged, $77 \%$ pegawai tergolong not engaged, dan $15 \%$ pegawai tergolong actively disengaged. 
Hanya tiga faktor saja yang diteliti pada penelitian ini, yaitu kepemimpinan etis, budaya organisasi, dan penghargaan dengan pertimbangan bahwa DJP telah menerapkan standar kompentesi untuk para pejabatnya yang meliputi kompetensi teknis (hard competency) dan kompetensi non teknis(soft competency).Unsur-unsur kompetensi non teknis(soft competency) tersebut sudah memenuhi aspek kunci kepemimpinan etis menurut Kalshoven,Den Hartog, dan De Hoogh (2011). Organisasi DJP juga sudah menerapkan budaya organisasi mengacu kepada nilai budaya kementerian keuangan sejak tahun 2007. DJP juga sudah memberikan penghargaan (rewards)yang relatif memadai kepada pegawainya dengan adanya renumerasi, program penghargaan kinerja, dan lain sebagainya.

Sebagai responden mewakili pegawai DJP dipilih Account Representative (AR) pada Kantor Pelayanan Pajak Pratama di lingkungan Kantor Wilayah Direktorat Jenderal Pajak ' $\mathrm{X}$ '.Pemilihan AR sebagai responden dengan pertimbangan : (1) tugas AR sudah melingkupi sebagian besar tugas utama KPP dan (2) populasi AR relatif besar dalam komposisi pegawai DJP yang meliputi sekitar $20 \%$ jumlah pegawai DJP.

\section{Kajian Literatur}

\section{Keterikatan Kerja (Work Engagement)}

Sejak mulai diwacanakan pada tahun 1990-an, masalah engagement pegawai telah mendapat perhatian luas dalam pengelolaan sumber daya manusia karena engagement pegawai merupakan pendorong kunci menuju keberhasilan organisasi (Lockwood, 2007). Tingkat engagement yang tinggi dapat meningkatkan kinerja organisasi. Dengan meningkatkan tingkat keterlibatan pegawai organisasi dapat mengharapkan peningkatan kinerja pegawai hingga20 \% dan penurunan kemungkinan pegawai meninggalkan organisasi hingga $87 \%$. Pegawai yang sangat engage memiliki kinerja $20 \%$ di atas kinerja rata-rata pegawai dan memiliki kecenderungan untuk tidak meninggalkan organisasi (Corporate Leadership Council Executive Summary, 2004).Tenaga kerja yang engage mampu memberikan diferensiasi berkelanjutan bagi organisasi dan keunggulan kompetitif yang signifikan (Singh dan Lalvani, 2015).

Banyak definisi diberikan tentang engagement. Erickson (2005, dalamMacey dan Schneider, 2008) menggambarkan engagement sebagai komitmen dan perasaan sayang. Suatu sikap yang menanamkan dalam diri sendiri keinginan untuk membantu organisasi supaya bisa berhasil mencapai tujuannya. Schaufeli (2002) menjelaskan engagement sebagai pikiran yang positif berhubungan dengan penunaian kerja yang dicirikan dengan vigor, dedikasi, dan absorption. Sifat vigor tergambar melalui energi yang tinggi dan mental yang ulet, keinginan untuk mengerahkan upaya dalam suatu pekerjaan, dan kegigihan ketika menghadapi 
kesulitan. Sifat dedikasi digambarkan sebagai suatu rasa berarti, antusiasme, inspirasi, bangga, dan tertantang. Absorption digambarkan dengan berkonsentrasi penuh, keasyikan yang mendalam dalam suatu pekerjaan, dimana waktu yang berlalu begitu cepat dan seseorang sulit melepaskan dirinya dari pekerjaan. Engagement menurut Singh dan Lalvani(2015) adalah jumlah total perilaku tempat kerja yang ditunjukkan oleh pegawai. Unsur perilaku dimaksudadalah kepercayaan pada organisasi, dorongan kerja untuk membuat segala sesuatu menjadi lebih baik, memahami konteks bisnis, menghormati dan mendukung orang lain dan kemauan untuk mempelajari keterampilan baru. Purcel (2012) berpendapat bahwa engagement adalah suatu kombinasi dari sikap (attitude) dan perilaku (behavior). Sikapnya adalah 'komitmen' dan perilakunya adalah 'mampu bekerja ekstra (going the extra mile)'.

Dalam risetnya, Kahn (1990) menemukan tiga kondisi psikologis yang mempengaruhipegawai untuk merasa terlibat (engage) atau tidak terlibat (disengage), yaitu kebermaknaan, rasa aman, dan eksistensi. Pegawai akan merasakan kebermaknaan secara psikologis apabila mereka merasa bahwa mereka memperoleh suatu hasil dari investasi kognitif, emosional, dan fisik mereka. Keamanan secara psikologis dirasakan apabila pegawai merasa dapat secara aman terlibat dalam suatu peran pekerjaan tanpa ketakutan atas konsekuensi yang tidak diinginkan terhadap status, citra diri, dan karir mereka. Eksistensi secara psikologis akan dirasakan apabila pegawai merasa bahwa mereka memiliki kemampuan kognitif, emosional, dan fisik untuk terlibat secara pribadi dalam suatu peran pekerjaan.

Biasanya pemakaian istilah "employee engagement" dan "work engagement" sering dipertukarkan, Namun keduanya masih dapat dibedakan bahwa work engangement mengacu pada hubungan karyawan dengan pekerjaannya, sedangkan employee engagement juga mencakup hubungan dengan organisasi.

\section{Kepemimpinan Etis (Ethical Leadership)}

Dalam studi perilaku kepemimpinan semakin berkembang wacana kepemimpinan yang berbasis nilai (value), salah satunya adalah wacana kepemimpinan etis. Brown, Trevino dan Harrison (2005) mendefinisikan kepemimpinan etissebagai penunjukkan tabiat normatif yang seharusnya melalui tindakan-tindakan personal dan hubungan antar personal serta memperkenalkan tabiat dimaksud kepada para pengikut melalui komunikasi dua arah, penguatan, dan pengambilan keputusan.

Ciri pemimpin etis dengan etika tinggi adalah bertanggung jawab, serius, dan akomodatif. Kepemimpinan etis mengandung dua dimensi penting : manajer bermoral dan pribadi bermoral. 'Manajer bermoral' mengacu pada sejauh mana seorang pemimpin 
menetapkan standar moral dan menggunakan penghargaan dan penalti untuk memastikan bahwa standar moral diikuti. 'Pribadi bermoral' mengacu pada sejauh mana seorang pemimpin menunjukkan perilaku yang selayaknya di tempat kerja seperti kejujuran, kepercayaan, dan kepeduliankepada orang lain. Pribadibermoral dipandang sebagai orang yang mudah didekati dan dapat diandalkan (Brown, Trevino, dan Harrison, 2005). Pemimpin etis tidak hanya membicarakan hal yang baik-baik tetapi mereka mempraktikkan apa yang mereka sampaikan dan secara proaktif menjadi panutan tentang penerapan kode etik (Brown dan Trevino, 2006).

Pemimpin etis dipandang bertanggung jawab untuk mengilhami nilai-nilai moral dan standar etika di antara pengikut mereka dan berperan sebagai panutan yang mempromosikan perilaku etis dan moral yang baik dengan mendorong hubungan organisasi dan karyawan yang pada gilirannya mengarahkan pengikut mereka untuk terikat secara emosional dengan organisasi mereka(Nelson dan Daniels, 2014).

Hubungan antara ethical leadership dan work engagement telah dijelaskan pada studistudi terdahulu.Studi yang dilakukan Macey, Schneider, Barbera, dan Young (2009; dalam Engelbrecht, Heine, dan Mahembe, 2014) menjelaskan bahwa pegawai memiliki kapasitas untuk engage apabila organisasi menyediakan informasi yang diperlukan dan kesempatan pelatihan untuk melakukan pekerjaan dengan baik. Demikian juga dukungan struktural yang berkontribusi terhadap kemampuan kinerja pegawai. Kepemimpinan etis menyediakan sumber daya tertentu terkait pekerjaan untuk membantu pegawai menyelesaikan pekerjaannya dengan efektif. Menurut Bakker dan Demerouti (2008; dalam Engelbrecht, Heine, dan Mahembe, 2014) sumber daya dimaksud berhubungan positif dengan keterikatan kerja karena memberikan pegawai bantuan yang diperlukan untuk menyelesaikan pekerjaannya.

Macey, Schneider, Barbera, dan Young (2009; dalam Engelbrecht, Heine, dan Mahembe, 2014) juga menemukan bahwa pegawai akan termotivasi untuk engage dalam pekerjaan bila mereka diperlakukan dengan hormat dan dianggap bernilai oleh organisasi. Menurut Kim dan Brymer (2011; dalam Engelbrecht, Heine, dan Mahembe, 2014) perilaku kepemimpinan etis mendorong kepuasan kerja para pengikutnya karena mereka diperlakukan secara fair dan merasakan kepedulian dan dukungan, yang akan mendorong sikap positif pengikut. Pegawai yang memiliki kepuasan tinggi akan termotivasi dan ingin melakukan upaya ekstra karena mereka memiliki komitmen yang lebih untuk melakukan pekerjaan yang berkualitas tinggi.

Selanjutnya Macey, Schneider, Barbera, dan Young (2009; dalam Engelbrecht, Heine, dan Mahembe, 2014) mengungkapkan bahwa ketika seorang pegawai mendapatkan kebebasan untuk membuat keputusan dan bertindak tanpa perlu berkonsultasi dengan atasan setiap waktu, hal ini akan menghasilkan keterikatan kerja. Bellingham (2003; dalam 
Engelbrecht, Heine, dan Mahembe, 2014) menyatakan bahwa kepemimpinan etis mau memberdayakan pegawai melalui pelatihan dan dukungan serta mereka ingin memberikan kebebasan kepada pegawainya untuk menunjukkan inisiatif melalui pemberian tanggung jawab dan kewenangan. Hal ini memberikan indikasi yang jelas bahwa kepemimpinan etis menyediakan kebebasan kepada pegawai untuk engage dalam pekerjaan mereka.

Dalam studinya Macey, Schneider, Barbera, dan Young (2009; dalam Engelbrecht, Heine, dan Mahembe, 2014) juga mengindikasikan bahwa pegawai akan engage dalam pekerjaannya apabila mereka mengetahui apa yang menjadi prioritas strategis organisasi dan bagaimana mereka berkontribusi terhadap tujuan organisasi melalui pekerjaan mereka. Kepemimpinan etis peduli dengan pegawainya dan kerap melakukan komunikasi dengan pegawainya (Brown dan Trevino, 2006; dalam Engelbrecht, Heine, dan Mahembe, 2014).

Engelbrecht, Heine, dan Mahembe (2014) menekankan dari hasil penelitiannya suatu kenyataan bahwa para pengikut memiliki engage dalam pekerjaannya apabila mereka menganggap bahwa pimpinan mereka berlaku etis.Melalui analisis regresi dalam penelitiannya, Den Hartog dan Belschank (2012) mengkonfirmasikan bahwa kepemimpinan etis dan keterikatan kerja memiliki hubungan yang positif.

\section{Budaya Organisasi (Organizational Culture)}

Menurut Ravasi dan Schultz (2006) budaya organisasi adalah seperangkat asumsi bersama yang membimbing apa yang terjadi dalam organisasi dengan menentukan perilaku yang sesuai untuk berbagai situasi Allaire dan Firsirotu (1984) secara lebih rinci menjelaskan bahwa budaya organisasi adalah sistem simbol-simbol tertentu yang dibentuk oleh kelompok masyarakat sekitar dan sejarah organisasi, kepemimpinan, dan peristiwa, kemudian dibagi, digunakan, dan dimodifikasi oleh para aktor dalam organisasi secara berbeda-beda berdasarkantindakan dan pemahaman dari kejadian-kejadian dalam organisasi. Budaya organisasi adalah alat yang ampuh untuk menafsirkan kehidupan dan perilaku organisasi. Pengertian ini menjelaskan bahwa budaya organisasi adalah produk dari pengalaman panjang suatu organisasi yang dirumuskan sebagai karakteristik dari organisasi tersebut.

Menurut Robbins (1996; dalam Mujiasih dan Ratnaningsih, 2012), budaya organisasi digambarkan sebagai nilai bersama, prinsip, tradisi, dan cara melakukan hal-hal yang mempengaruhi cara kerja anggota organisasi. Definisi budaya ini menyiratkan tiga hal. Pertama, budaya adalah persepsi. Maknanya adalah bahwa budaya bukan sesuatu yang dapat disentuh atau dilihat secara fisik, namun karyawan melihatnya berdasarkan apa yang mereka alami dalam organisasi. Kedua, budaya organisasi bersifat deskriptif. Hal ini berkaitan dengan 
bagaimana anggota memandang menggambarkan budaya bukan dengan apakah mereka menyukainya. Akhirnya, meskipun individu mungkin memiliki latar belakang yang berbeda atau bekerja pada tingkat organisasi yang berbeda, mereka cenderung menggambarkan budaya organisasi dengan istilah yang sama. Itulah aspek budaya bersama (Robbins, 1996; dalam Mujiasih dan Ratnaningsih, 2012).

Semua organisasi memiliki budaya, namun tidak semua budaya secara sama mempengaruhi perilaku dan tindakan karyawan. Budaya yang kuat (strong culture) -adalah kondisi ketika nilai-nilai utama dipegang dan dibagikan secara luas- memiliki pengaruh lebih besar pada karyawan daripada budaya yang lebih lemah(Robbins, 1996; dalam Mujiasih dan Ratnaningsih, 2012).Budaya yang berpengaruh besar terhadap pegawai dikenal dengan strong culture (budaya yang kuat) dan sebaliknya budaya yang tidak memiliki pengaruh terhadap perilaku pegawai dikenal dengan weak culture (budaya yang lemah).Menurut Cushway dan Lodge (2000; dalam Widyanti dan Agtriani, 2016), budaya organisasi merupakan sistem nilai organisasi dan akan mempengaruhi cara pekerjaan dilakukan dan cara para karyawan berperilaku. Dari definisi Cushway ini dapat disimpulkan bahwa budaya organisasi akan mempengaruhi cara pegawai melakukan pekerjaan dan berperilaku.

Hubungan organizational culture dengan work engagementdinyatakan oleh Smith (2017) bahwa budaya organisasi dapat memiliki dampak yang kuat bagi karyawan. Budaya yang positif dan terbuka dapat menciptakan kepercayaan dan kesetiaan antar karyawan, memberi semangat pada pekerjaan dan dedikasinya kepada perusahaan. Karyawan yang merasa nyaman dalam budaya lebih cenderung terlibat dalam pekerjaan dan perusahaan mereka yang dapat menginspirasi antusiasme dan produktivitas.

\section{Penghargaan (Reward)}

Penghargaan (reward) mengacu kepada apapun yang dipersepsikan oleh pegawai akan diperoleh dari nilai yang mereka hasilkan dari hubungan ketenagakerjaan dan meliputi semua jenis penghargaan, langsung dan tidak langsung, atau bersifat intrinsik dan ekstrinsik (Kimutai dan Sakataka, 2015). Tujuan dari penghargaan adalah untuk memaksimalkan pengaruh positif bahwa beragam penghargaan dapat menghadirkan motivasi, keterikatan kerja, komitmen organiasi dan kepuasan kerja (Manus dan Graham, 2003; dalam Kimutai dan Sakataka, 2015).

Pegawai perlu didorong 'bergerak lebih tinggi dan dalam' dari penugasan kerja standar dengan memperlihatkan dukungan, pembagian yang adil, dan penghargan yang konsisten, yang memperhatikan perubahan kebutuhan pegawai dan menyakinkan agar mereka mengerti bahwa sistem insentif dapat menguntungkan mereka apabila mereka engage dalam 
perilaku pelayanan yang bijaksana (Payne dan Weber, 2006; dalam Kimutai dan Sakataka, 2015).

Ada beragam bentuk penghargaan. Menurut Luthans dan Peter (2002; dalam Obicci, 2015) ada dua tipe dasar penghargaan, yaitu ekstrinsik dan intrinsik.Penghargaan ekstrinsik juga dikenal sebagai keuangan atau berwujud atau moneter- sebagian besar bersifat finansial. Penghargaan ini disebut 'ekstrinsik' karena berada di luar pekerjaan itu sendiri dan pihak lain yang mengendalikan ukurannya dan tidak terjamin apakah penghargaan tersebut akan diberikan atau tidak. Penghargaan ini terdiri dari elemen seperti gaji, tunjangan, keamanan kerja, promosi, iklim sosial, gaji yang kompetitif, kenaikan gaji, bonus prestasi, kompensasi waktu dan lain-lain (Mahoney dan Lederer, 2006, dalam Obicci, 2015).

Penghargaan intrinsik merupakan penghargaan psikologis yang diterima pegawai karena mengerjakan pekerjaan yang berarti dan mereka melakukannya dengan baik. Penghargaan intrinsik adalah perasaan internal individu tentang kepuasan kerja, pertumbuhan, otonomi dan kompetensi diri yang dialami individu selama karirnya (Obicci, 2015). Menurut Allen et. al. (2004; dalam Obicci, 2015) bentuk-bentuk penghargaan intrinsik tersebut adalah prestasi, tantangan, otonomi, tanggung jawab, variasi, pertumbuhan pribadi dan profesional, pengakuan status, pujian dari atasan dan rekan kerja, kepuasan pribadi, rasa harga diri, kepercayaan diri, kreativitas, kesempatan untuk menunjukkan keterampilan dankemampuan seseorang, serta umpan balik yang efisien.

Dari penjelasan di atas dapat disimpulkan bahwa terdapat dua jenis penghargaan, yaitu penghargaan intrinsik atau non moneter atau tidak bersifat uang dan penghargaan ekstrinsik atau penghargaan berupa uang (finansial) atau bersifat uang (moneter). Penghargaan, dengan demikian, adalah semua manfaat ekonomi maupun manfaat psikologis yang diberikan oleh organisasi kepada pegawai.

Berbagai jenis penghargaan memberikan pengaruh yang berbeda terhadap pegawai. Penghargaan moneter meningkatkan kepuasan langsung karyawan dan penghargaan nonmoneter sangat membantu sebagai bentuk pengakuan terhadap karyawan dan pengakuan tersebut merupakan alat motivasi bagi karyawan dan mengarah pada keterlibatan kerja (Burgess dan Ratto, 2003; dalam Waqas, 2014).

Penghargaan total adalah segala sesuatu yang dirasakan bernilai oleh pegawai sebagai hasil dari hubungan kerja dan mencakup semua jenis penghargaan, langsung dan tidak langsung, maupun intrinsik dan ekstrinsik. Komponen-komponen khas dari penghargaan total yang dijadikan sebagai pengungkit oleh pemberi kerja untuk memotivasi, mengikat, dan mempertahankan pegawai adalah gaji, manfaat-manfaat, lingkungan kerja, pembelajaran dan pengembangan (Amstrong, 2006). 


\section{Pengembangan Hipotesis}

\section{a. Hubungan Kepemimpinan Etis dan Keterikatan Kerja}

Den Hartog dan Belschak (2012) menemukan bahwa kepemimpinan etis berhubungan positif dengan keterikatan kerja. Engelbrecht, Heine, dan Mahembe (2014) menyatakan bahwa terdapat hubungan positif antara kepemimpinan etisdan keterikatan kerja. Demirtas (2015) menemukan bahwakepemimpinan etis secara langsung dan tidak langsung mempengaruhiketerikatan kerja.

Dalam penelitian mereka Engelbrecht dan Mahembe (2016) mengindikasikan terdapat hubungan positif antara kepemimpinan etis dan keterikatan kerja. Gaji dan Kassim (2017) menemukan bahwa kepemimpinan etis dan keterikatan kerja berhubungan secara signifikan. Sugianingrat, Yasa,Sintaasih, dan Subudi (2017) menyatakan dari hasil penelitian mereka bahwa kepemimpinan etis mempegaruhi keterikatan pegawai.

Rantika dan Yustina (2017) menemukan bahwa kepemimpinan etis berpengaruh secara signifikan terhadap keterikatan kerja. Demirtas,Hannah, Gok, Arslan, dan Capar (2017) menyimpulkan bahwa kepemimpinan etis memiliki pengaruh yang langsung dan signifikan terhadap keterikatan kerja.

Berdasarkan dari tinjauan literatur di atas maka diajukan hipotesis :

H1 :Kepemimpinan etis berpengaruh positif secara signifikan terhadap keterikatan kerjaAR pada KPP Pratama di lingkungan Kanwil DJP ' $X$ '.

\section{b. Hubungan Budaya Organisasi dan Keterikatan Kerja}

Barbars (2015) menyatakan bahwa budaya organisasi berhubungan positif dengan keterikatan kerja.Dalam penelitiannya pada objek yang lain Barbars (2017) kembali menyimpulkan bahwabudaya organisasi memiliki hubungan yang signifikan dengan keterikatan kerja.Dalam penelitiannya Naidoo and Martins (2014) menemukan bahwa seluruh dimensi budaya organisasiberkorelasi positif denganketerikatan kerja. Arifin, Troena,Djumahir, Rahayu (2014) menyatakan bahwabudaya organisasiberhubungan postif dengan keterikatan kerja.Dalam penelitian mereka yang lain, Arifin, Troena,Djumahir, Rahayu (2014) juga membuktikan hipotesis mereka bahwa budaya organisasi mempengaruhi keterikatan kerja.

Dari hasil penelitian mereka, Kalia danVerma (2017)mengemukakan bahwa semua elemen budaya organisasi berhubungan dengan elemen keterikatan kerja. Suharti dan Suliyanto (2012) mengungkapkan bahwa budaya organisasi berpengaruh terhadap keterikatan pegawai. Sadeli (2012) dalam penelitiannya menyimpulkan bahwa budaya organisasi berpengaruh terhadap keterikatan pegawai. 
Berdasarkan dari tinjauan literatur di atas maka diajukan hipotesis :

H2 :Budaya organisasi berpengaruh positif secara signifikanterhadap keterikatan kerja AR pada KPP Pratama di lingkungan Kanwil DJP ' $X$ '.

\section{c. Hubungan Penghargaan dan Keterikatan Kerja}

Dari penelitian mereka, Waqas dan Saleem (2014) menemukan fakta bahwa penghargaan memiliki pengaruh yang besar terhadap engagement pegawai. Hanem, Zulhafiza, dan Zulfadhli (2016) menyimpulkan bahwa terdapat hubungan yang positif antara penghargaan dan keterikatan kerja. Benazir (2014) dalam penelitiannya menemukan pengaruh positif penghargaan terhadap keterikatan pegawai. Dari studi yang dilakukannya, WorldatWork (2010) menyimpulkan bahwa total penghargaan mempengaruhi keterikatan pegawai. Pada penelitiannya Hoole dan Hotz (2015) menemukan bahwa terdapat hubungan total penghargaan dan keterikatan kerja, namun hubungan tersebut tidak terlalu signifikan dibandingkan variabel lain dalam penelitian tersebut. Obicci (2015) menemukan bahwa penghargaan, baik intrinsik maupun ekstrinsik, memiliki pengaruh yang sangat signifikan terhadap keterikatan pegawai.

Kimutai dan Sakataka (2015) meneliti hubungan tiga jenis penghargaan terhadap keterlibatan pegawai, yaitu manfaat keuangan langsung, manfaat keuangan tidak langsung, dan manfaat non keuangan. Temuan dari penelitian tersebut adalah semua jenis penghargaan tersebut berhubungan dengan keterlibatan pegawai dengan tingkat kekuatan dan daya tarik yang berbeda-beda.

Allameh, Sharifian, Masoumzadeh, dan Naeini (2014) menyimpulkan bahwa penghargaan memiliki pengaruh positif terhadap keterlibatan pegawai.Dalam penelitian mereka Victor dan Hoole (2017) menemukan data bahwa penghargaan mempengaruhi keterikatan kerja secara signifikan. Mesepy (2016) menyatakan bahwa penghargaan berpengaruh signifikan terhadap keterikatan pegawai.

Berdasarkan dari tinjauan 111iterature di atas maka diajukan hipotesis :

H3 : Penghargaanberpengaruh posisitf secara signifikan terhadap keterikatan kerjaAR di KPP Pratama di lingkungan Kanwil DJP ' $\mathrm{X}$ '.

\section{METODE PENELITIAN}

Penelitian ini dilakukan pada sembilan KPP Pratama di lingkungan Kanwil DJP X dengan objek penelitian adalah seluruh AR yang bekerja pada kantor tersebut. Dari 187 lembar kuisioner yang dibagikan, 165 kuisioner dikembalikan dan diisi dengan lengkap atau persentase keikutsertaan responden sebesar 88,24\%. 
Penelitian ini menjadikan keterikatan kerja sebagai variabel terikat dan kepemimpinan etis,budaya organisasi, dan penghargaan sebagai variabel bebas.Pengukuran variable keterikatan kerja dilakukan dengan menggunakan Utrecht Work Engagement Scale (UWES) Questionnaire yang dikembangkan oleh Schaufeli, Bakker, dan Salanova (2006).

Pengukuran variable kepemimpinan etik ini dilakukan dengan menggunakan kuisioner yang mengacu kepada Ethical Leadership Questionnaire (ELQ) yang dikembangkan oleh Yukl, Mahsud, Hassan, dan Prussia (2013). Pengukuran variabel budaya organisasi dilakukan dengan menggunakan kuisioner yang mengacu kepada Organizational Cultural Profile Revised Edition (OCPR) yang dikembangkan oleh Sarros dan Cooper (2005).

Penghargaan yang dalam penelitian ini dibedakan atas penghargaan yang berhubungan dengan uang (finansial) dan yang tidak berhubungan dengan uang (non finansial) diukur menggunakan kuisioner yang diambil dari studi yang dilakukan oleh Al-Nsour (2012).

\section{PEMBAHASAN}

Penentuan kelayakan (validitas) suatu item untuk digunakan atau tidak dalam penelitian digunakan batas nilai minimal korelasi 0,30 (Azwar, 1999; dalam Priyatno, 2012). Dari hasil pengujian didapatkan koefisien korelasi seluruh item dari semua variabel lebih besar dari 0.30 sehingga seluruh item pertanyaan dianggap valid.

Penentuan kehandalan (realibilitas) suatu variabel penelitian dapat dilihat dari hasil uji statistik cronbach alpha $(\alpha)$. Dari hasil pengujian diperoleh cronbach alpha variabel X1sebesar 0,943, cronbach alpha variabel X2 sebesar 0,921, cronbach alpha variabel X3sebesar 0,921, dan cronbach alpha variabel Y sebesar 0,899. Semua nilai cronbach alphat tersebut lebih besar dari 0,6 sehingga semua variabel dianggap reliabel/layak.

Penelitian ini juga sudah memenuhi prasyarat uji asumsi klasik yaitu uji normalitas, uji multikolinearitas, dan uji heteroskedastisitas.

Dari hasil uji koefisien determinasi $\left(\mathrm{R}^{2}\right)$ diperoleh nilai koefisien determinasi sebesar 0,985 . Hal ini berarti bahwa secara bersama-sama variabel kepemimpinan etis, budaya organisasi dan penghargaan mempunyai kontribusi menjelaskan faktor-faktor yang mempengaruhiketerikatan kerja AR di KPP Pratama di lingkungan Kanwil DJP ' $X$ ' sebesar $98.5 \%$, sedangkan sisanya $1.5 \%$ dijelaskan oleh variabel lain yang tidak diteliti atau tidak dimasukkan dalam model penelitian ini.

Hasil Uji-t dituangkan ke dalam sebuah persamaan regresi linear berganda seperti berikut :

$$
\mathrm{Y}=41,927+0,043 \mathrm{X} 1+0,118 \mathrm{X} 2+0,164 \mathrm{X} 3
$$


Dari persamaan di atas terlihat seluruh variabel independen memiliki koefisien regresi positif yang berarti bahwa kepemimpinan etis, budaya organisasi, dan penghargaan memiliki hubungan positif dengan keterikatan kerja pegawai.

Nilai signifikansi variabel kepemimpinan etis diperoleh sebesar 0,000. Nilai ini lebih kecil dari alpha 0,05 dan menghasilkan keputusan bahwa Ho ditolak dan H1 diterima sehingga dapat disimpulkan bahwa kepemimpinan etis berpengaruh positif secara signifikan terhadap keterikatan kerja AR pada KPP Pratama di lingkungan Kanwil DJP ' $X$ '.

Hasil pengujian ini sejalan dengan hasil penelitian Sugianingrat, Yasa,Sintaasih, dan Subudi (2017) yang menemukan bahwa kepemimpinan etis berpengaruh signifikan terhadap keterikatan kerja pegawai.

Hasil penelitian ini juga mengkonfirmasi hasil penelitian Rantika dan Yustina (2017) yang menemukan bahwa kepemimpinan etis berpengaruh signifikan terhadap keterikatan kerja. Kesimpulan yang sama diperoleh oleh Gaji dan Kasim (2017) dari penelitian mereka bahwa kepemimpinan etis berpengaruh positif dan signifikan terhadap keterikatan kerja.Dari penelitian mereka, Demirtas,Hannah, Gok, Arslan, dan Capar (2017) juga menyimpulkan bahwa kepemimpinan etis memilikipengaruh yang langsung yang positif dan signifikan terhadap keterikatan kerja.

Nilai signifikansi variabel budaya organisasidiperoleh sebesar 0,000. Nilai ini lebih kecil dari alpha 0,05 dan menghasilkan keputusan bahwa Ho ditolak dan H2 diterima sehingga dapat disimpulkan bahwa budaya organisasi berpengaruh positif secara signifikan terhadap keterikatan kerja AR pada KPP Pratama di lingkungan Kanwil DJP ' $X$ '.

Hasil pengujian ini sejalan dengan hasil dari dua kali penelitian Arifin, Troena,Djumahir, Rahayu (2014)pada tahun yang sama dengan objek penelitian berbeda yang menghasilkan kesimpulan yang sama bahwa budaya organisasi berhubungan positif dan signifikan dengan keterikatan kerja.Suharti dan Suliyanto (2012) dalam penelitian mereka juga membuat kesimpulan bahwa budaya organisasi berpengaruh terhadap keterikatan pegawai.Pada penelitian lain yang dilakukan oleh Sadeli (2012) juga dihasilkan kesimpulan bahwa budaya organisasi berpengaruh terhadap keterikatan kerja.

Nilai signifikansi variabel penghargaan diperoleh sebesar 0,000. Nilai ini lebih kecil dari alpha 0,05dan menghasilkan keputusan bahwa Ho ditolak dan H3 diterima sehingga dapat disimpulkan bahwa penghargaan berpengaruh positif dan signifikan terhadap keterikatan kerja AR pada KPP Pratama di lingkungan Kanwil DJP ' $X$ '.

Kesimpulan hasil pengujian hipotesis ketiga ini sejalan dengan hasil penelitian Victor dan Hoole (2017)bahwa penghargaan mempengaruhi keterikatan kerja secara signifikan. Dalam penelitiannya Mesepy (2016) juga menemukan bahwa penghargaan berpengaruh 
signifikan terhadap keterikatan pegawai.Hasil penelitian ini memperkuat temuan Benazir (2014) bahwa penghargaan berpengaruh positif terhadap keterikatan pegawai. Allameh, Sharifian, Masoumzadeh, dan Naeini (2014) juga menemukan di dalam penelitian mereka bahwa penghargaan memiliki pengaruh positif terhadap keterlibatan pegawai.

Dari nilai koefisien regresi masing-masing variabel, hasil penelitian ini juga menunjukkan bahwa di antara tiga faktoryang mempengaruhi keterikatan kerja, faktor penghargaan memiliki pengaruh terbesar terhadap keterikatan kerja AR dibandingkan dengan dua faktor lainnya. Hal ini dapat dipahami karena sejakdilakukan reformasi birokrasi Kementerian Keuangan Republik Indonesia mulai tahun 2012, para pegawai Direktorat Jenderal Pajak mendapatkan tambahan penghasilan berupa renumerasi sehingga mereka menerima penghasilan yang lebih besar dibandingkan aparat sipil negara lainnya.

\section{Kesimpulan}

Penelitian ini bertujuan untuk menguji model teoritis yang mencoba membuktikan pengaruh kepemimpinan etis, budaya organisasi, danpenghargaan terhadap keterikatan kerja. Data yang dikumpulkan dari 165 responden yaitu AR pada KPP Pratama di lingkungan Kanwil DJP ' $\mathrm{X}$ ' dan diolah menggunakan aplikasi SPSS memberikan kesimpulan bahwa kepemimpinan etis, budaya organisasi, danpenghargaan berpengaruh positif dan signifikan terhadap keterikatan kerja AR pada KPP Pratama di lingkungan Kanwil DJP ' $X$ '.

Hasil penelitian ini memberikan beberapa implikasi dalam pengembangan SDM ke depan,di antaranya :

1. Apabila suatu organisasi mampu mendorong terealisasinya karakter kepemimpinan etis pada diri para manajernya maka diharapkan hal tersebut dapat meningkatkan keterikatan kerja para bawahan mereka yang pada gilirannya akan memicu peningkatan kinerja bawahan dalam mewujudkan tujuan organisasi.

2. Apabila organisasi mampu tetap menjaga dan meningkatkan kualitas penerapan budaya organisasi maka diharapkan hal tersebut dapat semakin meningkatkan keterikatan kerja pegawai.

3. Organisasi perlu terus mengembangkan berbagai bentuk dan jenis penghargaan kepada para pegawainya. Peningkatan penghargaan finansial barangkali sulit untuk terus menerus dilakukan karena keterbatasan anggaran. Namun, organisasi dapat mengembangkan berbagai bentuk penghargaan non finansial seperti apresiasi kinerja yang meliputi lebih banyak aspek, penciptaan lingkungan dan suasana kerja yang semakin kondusif, dan halhal bersifat non finansial lainnya yang di dalam penelitian ini terbukti lebih besar mempengaruhi keterikatan kerja. 


\section{DAFTAR PUSTAKA}

Allaire, Y., Firsirotu, M.E., (1984). Theories of organizational culture. Organization study. Vol. 5, No. 3, 193-226.

Allameh, S.M., Sharifian, A., Masoumzadeh, A.,dan Naeini, S.G. (2014) :Investigating the relationship between organizational rewards and employee engagement (Case study of Foolad Derakhshan Company in Arak). International Journal of Management Academy, Vol. 2, No. 4, 1-9.

Al-Nsour, M. (2012) : Relationship between Incentives and organizational performance for employees in the Jordanian Universities. International Journal of Business and Management, Vol. 7, No. 1.

Arifin, F., Troena, E.A., Djumahir, Rahayu, M. (2014) :The Influence of organizational culture, leadership, and personal characteristics towards work engagement and its impacts on teacher's performance (A study on accredited high schools in Jakarta). International Journal of Business and Management Invention. Vol. 3 No. 1.

Arifin, F., Troena, E.A., Djumahir, Rahayu, M. (2014) :Organizational culture, transformational leadership, work engagement and teacher's performance : Test of a model. International Journal of Education and Research. Vol. 2 No. 1.

ASNRI (2016, Mei 29). Sejarah, maksud, filosofi, dansegalahaltentangnilainilaikementeriankeuangan. Oktober 10, 2017. http://asnri.com/

Badan Pendidikan dan Pelatihan Pusdiklat Pajak (2014).Bahan Ajar Kapita Selekta Soft Competency.Jakarta.

Barbars, A. (2015) : Interaction between organizational culture and work engagement in an IT department within financial institution, Journal Business Management, No. 12.

Barbars, A. (2017) : Interaction between organizational culture and work engagement in the information and communicatioan technology sector in Latvia. Journal Business Management, No. 12, 84-100.

Benazir, N.I. (2015) : Impact of rewards and leadership on the employee engagement in conventional banking sector of Southern Punjab. International Letters of Social and Humanistic Sciences. Vol. 57, 30-34.

Brown, M.E., Treviño, L.K., (2006). Ethical leadership: A review and future directions.The Leadership Quarterly 17, 595-616.

Brown, M.E., Trevino, L.K., dan Harrison, D.A. (2005) : Ethical leadership: A social learning perspective for construct development and testing. Organizational Behavior and Human Decision Processes, Vol. 97, 117-134.

Corporate Leadership Council Executive Summary(2004) : Driving performance and retention through employee engagement. Washington, DC: Corporate Executive Board.

Demirtas, O. (2015) : Ethical leadership influence at organizations: Evidence from the field. Journal of Business Ethics, Vol. 126, 273-284.

Demirtas, O., Hannah, S. T., Gok, K., Arslan, A., dan Capar, N. (2017) : The moderated influence of ethical leadership, via meaningful work, on followers' engagement, organizationaliIdentification, and envy. Journal of Bussiness Ethics, Vol. 145, 183-199.

Den Hartog, D.N. dan Belschak, F.D. (2012) : Work engagement and Machiavellianisme in the ethical leadership process. Journal of Business Ethics.107, 35-47.

Departemen Keuangan Republik Indonesia (2007). Kamus Kompetensi Departemen Keuangan Republik Indonesia.

Dessler, H. (2005). Human Resource Management. Pearson Prentice Hall, New Jersey.

Direktorat Jenderal Pajak. Laporan Tahunan 2010 Direktorat Jenderal Pajak, Kementerian Keuangan Republik Indonesia

Direktorat Jenderal Pajak. Laporan Tahunan 2013 Direktorat Jenderal Pajak, Kementerian Keuangan Republik Indonesia 
Engelbrecht, A.S., dan Mahembe, B. (2016). Integrity, ethical leadership, trust and work engagement. Leadership \& Organization Development Journal Vol. 38 No. 3, 2017, 368-379.

Engelbrecht, A.S., Mahembe, B., dan Heine, G., (2014). The influence of ethical leadership on trust and work engagement: An Exploratory Study. SA Journal of Industrial Psychology, 40(1).

Gaji, M.B., Kassim, R., dan Raju, M.V. (2017) : Integrity, trust and Nigerian banks' employeeengagement. International Journal of Business Management and Economic Research, Vol 8, No. 4, 982-986.

Ghozali, I. (2011). Aplikasi analisis multivariate dengan program SPSS. Semarang: Badan Penerbit Universitas Diponegoro.

Hakim, L. (2015). Karakteristik budaya organisasi kuat sebagai upaya meningkatkan kinerja industri di Batik Danar Hadi Surakarta. BENEFIT Jurnal Managemen dan Bisnis. Vol. 19. No. 2. 196-205.

Hanim, F., Zulhafiza, dan Zulfadhli, M. (2016) : Sustainability in employment: Reward system and work engagement. Procedia Economics and Finance. Vol 35, 699 - 704.

Hoole, C. dan Hotz, G. (2016) :The Impact of a total reward system of work engagement. SA Journal of Industrial Psychology. Vol. 42, No. 1, 1-14.

Kahn, W.A. (1990) : Psychological conditions of personal engagement and disengagement at work. Academy of Management Journal. Vol. 33, No. 4, 692-724.

Kalia, N. danVerma, Y.S. (2017): Organizational culture and employee engagement : An interrelationship study in hospitallity industry of Himachal Pradesh. International Journal of Human ResourceManagement and Research. Vol. 7, 13-22.

Kalshoven K., Den Hartog, DN., dan De Hoogh, AHB. (2011). Ethical leader behaviour and big five factors of personality. Journal of Business Ethics. No.107, 35-47.

Kimutai, K.A.dan Sakataka, W. (2015) : Effect of reward on employee engagement and commitment at Rift Valley Bottlers Company. International Academic Journal of Human Resource and Business Administration. Vol. 1, No. 5, 36-54.

Lockwood, N.R. (2007) : Leveraging employee engagement for competitive advantage: HR's strategic role. SHRM Research Quarterly.

Macey, W.H. dan Schneider, B. (2008): The meaning of engagement. Industrial and Organizational Psychology. Vol.1. 3-30.

Mesepy, S.S. (2016) : The Impact of rewad and recognition on employee engagement at PT Bank Sulutgo, Madano. Jurnal Berkala Ilmiah Efisiensi. Volume 16 No. 01.

Mujiasih, E. dan Ratnaningsih, I.Z. (2012) : Meningkatkan work engagement melalui gaya kepemimpinan transformasional dan budaya organisasi. Tidak Diterbitkan. Fakultas Psikologi Universitas Diponegoro Semarang.

Naidoo, P. and Martins, N. (2014) : Investigating the relationship between organizational culture and work engagement. Problems and Perspectives in Management, Vol. 12, No. 4.

Nelson, J.A. dan Daniels, M.K. (2014) : Leadership, perceptions, and turnover intentions: Why stay?. Electronic Journal of Business Ethics and Organization Studies. Vol. 19, No. 1.

Obicci, P.A. (2015) : Influence of extrinsic and intrinsic rewards on employee engagement. Management Studies and Economic Systems, Vol. 2, No.1, 59-70.

Priyatno, D. (2013). Belajar cepat olah data statistik dengan SPSS. Yogyakarta : Penerbit Andi.

Purcel, J. (2012) :The limits and possibilities of employee engagement. Warwick Papers in Industrial Relations, No. 96.

Rantika, S.D. dan Yustina, A.I.(2017) : Effects of ethical leadership on employee wellbeing : The mediating role of psychological empowerment. Journal of Indonesian Economy and Business. Vol. 32, No. 2, $121-137$. 
Ravasi, D. danSchultz, M., (2006). Responding to organizational identity threats:Exploring the role of organizational culture. Academy of Management Journal. Vol. 49, No. 3, 433-458.

Republik Indonesia, Keputusan Menteri Keuangan nomor 1227/KM.1/2016 tentang Pedoman Pengembangan Talent dan Mekanisme Mentoring Dalam Manajemen Talenta Kementerian Keuangan.

Republik Indonesia, Keputusan Menteri Keuangan nomor 312/KM.01/2011 tentang Nilai-Nilai Kementerian Keuangan.

Republik Indonesia, Keputusan Menteri Keuangan nomor 98/KM.01/2006 tentang Account Representative pada Kantor Pelayanan Pajak yang Telah Mengimplementasikan Organisasi Modern.

Republik Indonesia, Peraturan Menteri Keuangan nomor 184/KM.01/2010 tentang Organisasi dan Tata Kerja Kementerian Keuangan.

Republik Indonesia, Peraturan Presiden Republik Indonesia Nomor 81 Tahun 2010 tentang Grand Design Reformasi Birokrasi 2010-2025.

Richardson, A., Cook, J., dan Hofmeyr, K. (2011) : How leaders generate hope in their followers. South African Journal of Labour Relations, Vol. 35, No. 2, 47-66.

Sadeli, J. (2012) : The influence of leadership, talent management, organizational culture and organizational support on employee engagement. International Research of Journal Business Studies. Vol. 5, No. 3.

Santoso, S. (2001). SPSS versi mengolah data statistik secara profesional. Jakarta : PT. Elex Media Komputindo.

Sarros, J.C. dan Densten, I.L. (2005) : The organizational culture profile revisited and revised: An Australian perspective. Australian Journal of Management, Vol. 30, No. 1.

Schaufeli, W.B., Salanova, M., dan Bakker, A.B. (2006): The measurement of work engagement with a short questionnaire : A cross-national study. Educational and Psychological Measurement. Vol. 66, No. 4, 701-716.

Schaufeli, W.B., Salanova, M., Roma, V.G., dan Bakker, A.B. (2002) : The measurement of engagement and burnout : A two sample confirmatory factor analytic approach.Journal of Happiness Studies, Vol. 3,71-92.

Sekaran, Uma, (2003). Research methods for business : A Skill-Building Approach. 4th Edition. America : John Wiley \& Sons Inc.

Singh, P. dan Lalvani, J. (2015) :An exploratory study on employee engagement and its impact on organizational performance. International Journal of Research in Management \& Business Studies. Vol. 2, No.1.

Smith, E. (n.d). Organizational culture employee engagement. Oktober 10, 2017. http://smallbusiness.chron.com/

State of Global Workplace (2013) : Employee engagement insights for business leaders worldwide. Gallup.

Sugianingrat, I.A.P.W., Kerti Yasa, N.N., Sintaasih, D.K., dan Subudi, M. (2017) :The influence of ethical leadership on employee performancethrough employee engagement. IOSR Journal Of Humanities And Social Science, Vol. 22, No. 12.

Sugiyono (2007). Metode penelitian. Jakarta: CV. Alfa Beta.

Suryabrata, S., (2000). Metode penelitian. Jakarta : PT. Raja Grafindo Persada.

Tahun 2016 Jumlah Pegawai Pajak Meningkat Dua Kali Lipat. Oktober 1, 2017. http://www.beritasatu.com/makro/

Victor, Janine dan Hoole, Crystal (2017) :The influence of organisational rewards on workplace trust and work engagement. Journal of Human Resource Management. Vol. 15.

Waqas, Z. Dan Saleem, S. (2014) : The effect of monetary and non-monetary rewards on employee engaagement and firm performance. European Journal of Business and Management. Vol.6, No. 31.

White, B., (2006). Employee engagement report. 
Widyanti, A. dan Agtriani, A. (2016). Budaya organisasi yang mendukung keselamatan pasien di rumah sakit. Jurnal Teknik Industri, Vol. 18, No. 2, 95-102.

WorldatWord (2010) : The impact of rewards programs on employee engagement.

Yukl, G., Mahsud, R., Hassan, S., dan Prussia, G. (2013): An improved measure of ethical leadership. Journal of Leadership \& Organizational Studies, Vol. 20., No. 1. 